\title{
Knowledge donation and knowledge collection patterns in a free software community
}

\author{
Andrea Raymundo Balle, PUCRS, Business School, Brazil, arballe@gmail.com \\ Carla Curado, ADVANCE/CSG, ISEG, Universidade de Lisboa, Portugal, \\ ccurado@iseg.ulisboa.pt
}

Mírian Oliveira, PUCRS, Business School, Brazil, miriano@pucrs.br

\begin{abstract}
This study aims to understand which combinations of tools and activities performed by members of a free software community lead to knowledge sharing. This paper reports a qualitative study developed using data from a worldwide Free Software Community (FSC). We've applied Fuzzy Set Qualitative Comparative Analysis ( $\left.f_{s} Q C A\right)$ technique, which offers alternatives configurations leading to both the outcomes and their absence. Results show that there is no solution leading to the absence of knowledge collection; there are several and alternative combinations leading to knowledge collection, knowledge donation, and both knowledge sharing processes. There are also some combinations leading to the absence of knowledge donation or the absence of both processes.
\end{abstract}

Keywords: Knowledge donation, knowledge collection, free software community, fuzzy set qualitative comparative analysis (fsQCA).

\section{Introduction}

Knowledge sharing (KS) provides several benefits for companies, such as greater knowledge sustainability, improvements in response time, productivity, learning, innovative capacity, organizational processes, and organizational performance (Gonzalez \& Chakraborty, 2014; Karkoulian, Harake \& Messarra, 2010; Matherly \& Al Nahyan, 2015; Tseng, 2010). KS is necessary for an organization to grow in a sustainable and competitive way (Grant, 1996). However, it is difficult to share knowledge because it is initially generated and stored in people's minds (Chow \& Chan, 2008). Tools can facilitate and increase KS, because they motivate active collaboration among people (Ranjan, 2011). One of the most appropriate contexts for KS research are free software communities (FSC) (Iskoujina \& Roberts, 2015). Free software is a type of computer software that can be run, copied, distributed, studied, changed, and improved by its users without restrictions (Stallman, 2015). FSC are communities of practice in which voluntary members gather online to produce and give support to a free software (Endres, Endres, Chowdhury, \& Alam, 2007; Carillo \& Okoli, 2008; O'Reilly, 1999). The centre of the FSC are collaboration and KS activities (Endres et al., 2007; Shen, 2005). Based on the above, the objective of this study is to understand which combinations of tools and activities performed by members of FSC lead to KS processes on these communities. This paper is organized as follows: the next section (KS \& FSC) situates the main concepts of the work on the literature and is 
followed by the research method (Methods \& Sample), the analysis (sections Conditions \& Outcomes, Analysis \& Results, as well as Causal Configurations), and it ends presenting the conclusions of the study (Discussion \& Conclusions).

\section{Knowledge Sharing and Free Software Communities}

Knowledge is a strategic resource for organizations (Naim \& Lenkla, 2016) usually attributed to the individual, but a large amount of knowledge is collectively generated and maintained (Brown \& Duguid, 1998). Therefore, it's important for companies to manage their knowledge to create value, facilitate organizational learning and guarantee a sustainable competitive advantage (Grant, 1996; Nobre \& Walker, 2011). Knowledge management is composed of the processes of creation, storage/retrieval, sharing and application of knowledge (Alavi \& Leidner, 2001). One of the most relevant processes of knowledge management is KS (Naim \& Lenkla, 2016; Shin, 2004; Velmurugan, Kogilah, \& Devinaga, 2010; Yang \& Chen, 2007). KS is a dynamic and interactive process, which happens when an individual wants to share and acquire knowledge from other individuals to build competences (Naim \& Lenkla, 2016) and create new knowledge (Song, 2014). Van der Hooff and De Ridder (2004) divided KS in two processes: donation and collection. Donation is the act of communicating your intellectual capital to others; collection is the act of consulting the intellectual capital of another individuals. During KS, the knowledge of the provider is converted to the receiver through a variety of mechanisms and tools (Daghfous \& Ahmad, 2015), like phone conversations, team meetings, intranets, document management systems, groupware applications, video/audio presentations, phone/video conferencing blogs, wikis, social media, e-mail lists, chats or forums (Hendricks, 1999; Majchrzak et al., 2000; Panahi, Watson, \& Partridge, 2013; Wenger et al., 2005). The use of KS tools increases adaptability, effective data retrieval, easiness to reach all domains, and gives an incentive for collaboration among the members of an organization (Ranjan, 2011). Another way to encourage $\mathrm{KS}$ is through the creation of communities of practice (Wenger \& Snider, 2000). Communities of practice are groups of people with mutual relations that maintain a regular flow of information between them, enabling the generation of new knowledge (Lave \& Wenger, 1991). Some communities of practice are organizational, used as a form to manage and share knowledge through a firm (Scarso \& Bolisani, 2007), but other are groups of people that not necessarily work together, but they meet to share knowledge because they find the interactions valuable (Wenger, McDermott, \& Snider, 2002). Even in organizational contexts, communities are selfmanageable (Du Plessis, 2008) and focus on a specific knowledge domain (Scarso \& Bolisani, 2007). Communities of practice do not necessarily demand physical meetings of the participants - one popular tool for KS is the employment of virtual communities of practice (Chen, Chang, \& Liu, 2012), where the interactions happen in the cyberspace, supported by information technology (Hsu et al., 2007). The members of virtual communities maintain a high level of engagement online, even with a large number of participants, making the virtual CoPs an environment conducive to learning (Zhang \& Watts, 2008). A type of virtual community of practice indicated by many authors are the FSCs (Krishnamurthy, 2003; Ye \& Kishida, 2003; Wasko \& Faraj, 2005). A FSC is an organized form of support and production of free software, where the members are volunteers, usually working long distance and being both developers and consumers of that free software (Casaló, Flavián, \& Guinalíu, 2010; Demazière, Horn, \& Zune, 
2007). The purpose of the community isn't only for its members to acquire individual knowledge, but also to collectively build and share knowledge (Barcellini, Détienne, Burkhardt, $\&$ Sack, 2008). Knowledge shared in FSC is an open knowledge, which means that every person has the freedom to use it, to reuse it, and to redistribute it without restrictions (Molloy, 2011). Members of FSC play many different roles. Madanmohan and Navelkar (2004) divided the roles in core organizers, experts, problem posers, implementers, integrators, institutionalisers, and philosophers. Jensen and Scacchi (2007) defined the organizational hierarchy of free software project as an "onion", where members gravitate towards the centre and have the following roles: passive users, active users, developers, project managers, community managers, and core developers. Reis and Fortes (2002) identified roles more specific to activities developed on the community, like design, reviewers, developers, quality assurance, or bug triage. But, as pointed by de Laat (2007), these divisions are not exhaustive, and the list can be endless, depending on the characteristics of the project. In many communities, a mailing list is used as the main source for coordinating development and support activities, but other technologies can be used to share knowledge (Sowe, Stamelos, \& Angelis, 2008). FSC rely on asynchronous communication tools, such as e-mail lists, wiki, blogs, forums, discussion panels, among others (Wenger et al., 2005), due to their distributed characteristics, they have participants in different parts of the globe and different time zones. In addition, communities use various communication technologies such as Internet Relay Chat (IRC), chats, Instant Messengers; or information technologies like sites or servers for reporting bugs (Nafus et al., 2006; Carillo \& Okolli, 2009; Sowe et al., 2008; Sowe, Stamelos, \& Angelis, 2008).

\section{Methods and Sample}

We adopted a qualitative approach using Fuzzy Set Qualitative Comparative Analysis (fsQCA), to identify the necessary, the sufficient, and the core conditions leading to the KS processes in the study. This study uses data from 20 interviews that took place at a world meeting involving 600 members of the FSC, which has approximately 400,000 participants in total. The interviewees were chosen randomly out of the participants who were sitting in the conference rooms and halls between sessions, with efforts to make the sample diverse in age, gender, and country. The members of the FSC that were available and decided to join this study were not rewarded for their participation. The collaboration with this study was completely voluntary and free from any pressure to participate. Six out of the 20 interviewees $(30 \%)$ are software developers; five (25\%) work with technology, in other positions (Information Technology (IT) consultant, technology entrepreneur, software engineer, network administrator, \& software quality analyst); two (10\%) are unallocated but are originally from the technology area; the remaining are students, managers, advertising, or salesmen (see Table 1 for more details). 
Table 1. Descriptive Statistics of Members of the FSC Interviewed for the Study $(n=20)$

\begin{tabular}{|c|c|c|c|c|c|}
\hline Interviewee & Country & Age (*) & Gender & $\begin{array}{c}\text { Education } \\
\text { level }(* *)\end{array}$ & $\begin{array}{c}\text { Seniority at the } \\
\text { FSC }(*)\end{array}$ \\
\hline 1 & Paraguay & 22 & $\mathrm{~F}$ & 2 & 4 \\
\hline 2 & Brazil & 27 & $\mathrm{M}$ & 2 & 10 \\
\hline 3 & Argentina & 24 & $\mathrm{M}$ & 2 & 6 \\
\hline 4 & Paraguay & 28 & $\mathrm{M}$ & 3 & 4 \\
\hline 5 & United States of America & 28 & $\mathrm{M}$ & 4 & 5 \\
\hline 6 & Mexico & 31 & $\mathrm{M}$ & 3 & 6 \\
\hline 7 & France & 28 & $\mathrm{M}$ & 4 & 2 \\
\hline 8 & Kenya & 24 & $\mathrm{~F}$ & 3 & 2 \\
\hline 9 & United States of America & 18 & $\mathrm{M}$ & 1 & 2 \\
\hline 10 & United States of America & 44 & $\mathrm{~F}$ & 4 & 10 \\
\hline 11 & Senegal & 25 & $\mathrm{M}$ & 2 & 3 \\
\hline 12 & Japan & 31 & $\mathrm{M}$ & 3 & 11 \\
\hline 13 & Brazil & 28 & $\mathrm{M}$ & 3 & 5 \\
\hline 14 & Zimbabwe & 22 & $\mathrm{M}$ & 2 & 1 \\
\hline 15 & Brazil & 32 & $\mathrm{M}$ & 4 & 1 \\
\hline 16 & United States of America & 33 & $\mathrm{M}$ & 3 & 5 \\
\hline 17 & Brazil & 38 & $\mathrm{M}$ & 2 & 13 \\
\hline 18 & Canada & 35 & $\mathrm{M}$ & 2 & 10 \\
\hline 19 & United States of America & 28 & $\mathrm{M}$ & 3 & 2 \\
\hline 20 & Israel & 19 & $\mathrm{M}$ & 1 & 1 \\
\hline
\end{tabular}

$\left(^{*}\right)$ - Measured in years; $(* *)-1=$ undergraduate; $2=$ attending a graduation program; $3=$ graduated; $4=$ postgraduated; $F=$ Female; $M=$ Male

This study considers KS processes as outcomes: Knowledge Donation (Don), Knowledge Collection (Col), and the combination of both: Knowledge exchange intensity (Int); and the absence of those: $\sim$ Don, $\sim \mathrm{Col}$, and $\sim$ Int (represented by the use of " $\sim$ " previous to the outcome). Causal conditions in the fsQCA analysis in this study involve the seniority of the member in the FSC (Sen) and the tools that the members mostly use. Activities and tools considered in this study are: Technical activities (Tec); Social activities (Soc); Use of Asynchronous tools (Asyn); Use of Synchronous tools (Syn); Use of external tools (Ext). Tec involve programming, quality, documentation and support. Tec are directly linked to the software creation cycle (Sommerville, 2003), and are essential to the community's purpose. Soc gather event organization, evangelism (ambassadors of organizational technologies) and marketing. Soc are important because communities are mostly composed of volunteers (Endres, Endres, Chowdhury, \& Alam, 2007), so the social and hedonistic dimensions of the community are incentives for participation and KS (Bonaccorsi \& Rossi, 2003; Iskoujina \& Roberts, 2015; Ulhoi, 2004). Asyn, Syn and Ext involve eight KS tools. The most commonly mentioned tool is mailing list, the most used tool in the FSC (Sowe, Stamelos, \& Angelis, 2008). Asyn are cited more often than Syn: referral sites, bug reporting system, and wiki are more used than instant communication tools such as IRC and Real Time Video. Ext regard blogs and sites external to the community. 


\section{Conditions and Outcomes}

fsQCA uses data ranging from 0 to 1 , so it requires calibration. Calibration is the process of classifying conditions and outcomes from full membership (1) to full non-membership (0), this way different condition levels represent meaningful groups (Crilly et al., 2012; Ragin, 2008). The calibration procedure implies a theoretical and empirical knowledge on the variables (Ragin, 2005; 2008). Regarding the outcomes Col and Don, as well as the conditions Syn and Ext, these were coded 1 for "presence" and 0 for "absence" (Ragin, 2006). The Int outcome data set was generated using the fsQCA software function "variables $\rightarrow$ compute $\rightarrow$ fuzzyand" combining Col and Don. High levels of Int reflect simultaneous high levels of Don and Col, on the contrary, the absence of Int reflects simultaneous absence of Don and Col. Following Ragin (2008) we've defined different classifications for different categories in the Tec, Soc, Asyn, Syn, and Ext conditions, as well as the required anchors to calibrate the Sen condition. The particularities of the conditions and outcomes, the descriptive statistics, along with the cuts used for calibration, are presented in Table 2.

Table 2. Descriptive Statistics and Calibrations of Causal Conditions and Outcomes $(n=20)$

\begin{tabular}{|c|c|c|}
\hline Causal Conditions and Outcomes & Descriptive Statistics & Calibration \\
\hline Technical activities (Tec) & $\begin{array}{c}1-40 \% \\
0.5-40 \% \\
0-20 \%\end{array}$ & $\begin{array}{c}1=\text { Engage in two or more activities } \\
0.5=\text { Engage in one activity } \\
0=\text { Engage in no activities }\end{array}$ \\
\hline Social activities (Soc) & $\begin{array}{c}1-5 \% \\
0.66-35 \% \\
0.33-15 \% \\
0-45 \%\end{array}$ & $\begin{array}{c}1=\text { Engage in three activities } \\
0.66=\text { Engage in two activities } \\
0.33=\text { Engage in one activity } \\
0=\text { Engage in no activities }\end{array}$ \\
\hline Use of Asynchronous tools (Asyn) & $\begin{array}{c}1-50 \% \\
0.66-15 \% \\
0.33-20 \% \\
0-15 \%\end{array}$ & $\begin{array}{c}1=\text { Uses three or more tools } \\
0.66=\text { Uses two tools } \\
0.33=\text { Uses one tool } \\
0=\text { no tools }\end{array}$ \\
\hline Use of Synchronous tools (Syn) & $\begin{array}{l}1-35 \% \\
0-65 \%\end{array}$ & $\begin{aligned} & 1=\text { Uses tools } \\
0= & \text { Does not use tools }\end{aligned}$ \\
\hline Use of external tools (Ext) & $\begin{array}{l}1-25 \% \\
0-75 \%\end{array}$ & $\begin{aligned} & 1=\text { Uses tools } \\
0= & \text { Does not use tools }\end{aligned}$ \\
\hline $\begin{array}{l}\text { Seniority of the member in the } \\
\text { FSC (Sen) }\end{array}$ & $\begin{array}{l}\mu=5.15 ; \sigma=3.65 \\
\min =1 ; \max =13\end{array}$ & $\begin{array}{l}\text { Cuts at } 0.9 ; 0.5 ; 0.1 \\
\text { Cuts at } 8 ; 4.5 ; 1.5\end{array}$ \\
\hline Knowledge Donation (Don) & $\begin{array}{l}1-60 \% \\
0-40 \% \\
\end{array}$ & $\begin{array}{c}1=\text { Donates knowledge } \\
0=\text { Does not donate knowledge }\end{array}$ \\
\hline Knowledge Collection (Col) & $\begin{array}{l}1-75 \% \\
0-25 \%\end{array}$ & $\begin{aligned} & 1=\text { Collects knowledge } \\
0= & \text { Does not collect knowledge }\end{aligned}$ \\
\hline
\end{tabular}

$\mu=$ average, $\sigma=$ standard deviation, min $=$ minimum, max $=$ maximum 


\section{Analysis and Results}

Causal conditions are assessed for necessity and sufficiency. The causal condition's degree of necessity indicates the extent to which it is needed to achieve the outcomes. Necessary conditions should present a consistency score exceeding the threshold of 0.90 (Rihoux \& Ragin, 2009). The only existing necessary condition is $\sim$ Soc which is necessary for $\sim$ Col. The causal condition's degree of sufficiency shows the extent to which it can be related to the explanation of the outcome (Fiss, Sharapov, \& Conqvist, 2013). The sufficient condition sets are also designated as configurations (of several causal conditions leading to the outcome in question). There are two configurations leading to Col. Regarding the outcome Don, results show three configurations, as well as two configurations leading to Int. Regarding the absence of the outcomes, there are no configurations leading to $\sim \mathrm{Col}$, since it was not possible to identify sufficiency relations is the truth table (inclusion scores were not respected) and therefore it was not possible to derivate complex, parsimonious and intermediate solutions (Thiem \& Duşa, 2013). In other words, we were not able to identify a single combination of conditions linked to $\sim$ Col complying with the suggested limits in the literature (Rubinson \& Ragin, 2007). Regarding the outcome $\sim$ Don, results show two configurations, and there are three configurations leading to $\sim$ Int. All the configurations as well as the reported intermediate solutions regarding the presence and absence of the outcomes present consistency levels that respect the threshold of 0.80 suggested by Ragin (2008), Crilly (2011), or Fiss (2011). Consistency reflects the extent to which the cases share a given combination of conditions agree in presenting the outcome in question (Ragin, 2008). Coverage reflects how much of the variation in the outcome is accounted for by a causal condition or combination (Ragin, 2006) similar to the $\mathrm{R}^{2}$ regarding linear regressions (Fiss et al., 2013). Specifically, unique coverage shows the relative importance of each particular configuration (Fiss, 2011).

\section{Causal Configurations}

Following the best processes, we report the solutions (Tables 3, 4, \& 5) presenting the causal configurations leading to the outcomes, as well as (Tables $6 \&$ 7) the causal configurations leading to the absence of the outcomes. There are 64 different combinations of logical remainders allowed by the variables in the study. There are 10 combinations in each of the truth tables for each outcome. Core conditions are the ones included in both the parsimonious and intermediate solutions, while peripheral conditions are only part of the intermediate solution (Fiss 2011; Fiss et al., 2013; Ragin, 2008).

For all Tables: Sen $=$ seniority of the member in the FSC; Tec $=$ Technical activities; $\mathrm{Soc}=$ Social activities; Asyn = Use of Asynchronous tools; Syn = Use of Synchronous tools; Ext $=$ Use of external tools; full black circles $(\bullet)$ indicate the presence of a condition, and center white circles $(\mathrm{O})$ indicate its absence. Large open circles indicate core conditions, small circles indicate peripheral conditions. Blank spaces indicate condition does not contribute to the configuration. 
Table 3. Causal Configurations Leading to $\mathrm{Col}$

\begin{tabular}{|c|c|c|c|c|c|c|c|c|c|}
\hline \multicolumn{10}{|c|}{ Col = f(Sen, Tecn, Soc, Asyn, Syn, Ext) } \\
\hline \multirow[t]{2}{*}{ Configurations } & Sen & Tec & Soc & Asyn & Syn & Ext & \multicolumn{2}{|c|}{ Coverage } & Consistency \\
\hline & & & & & & & raw & unique & \\
\hline 1 & $\circ$ & ? & • & & - & $\circ$ & 0.088000 & 0.088000 & 1.000000 \\
\hline 2 & $\bullet$ & ○ & $\circ$ & ? & ? & & 0.179305 & 0.179305 & 1.000000 \\
\hline \multicolumn{10}{|c|}{ Solution coverage: 0.267305} \\
\hline Solution consist & $y: 1.0$ & 000 & & & & & & & \\
\hline
\end{tabular}

Table 4. Causal Configurations Leading to Don

\begin{tabular}{ccccccccccc}
\hline \multicolumn{7}{c}{ Don $=\mathbf{f}($ Sen, Tecn, Soc, Asyn, Syn, Ext) } \\
\hline Configurations & Sen & Tec & Soc & Asyn & Syn & Ext & \multicolumn{2}{c}{ Coverage } & Consistency \\
\hline & & & & & & & raw & unique & \\
\hline 1 & $\circ$ & $\circ$ & $\bullet$ & $\bigcirc$ & $\bigcirc$ & $\circ$ & 0.152500 & 0.068333 & 1.000000 \\
\hline 2 & $\circ$ & $\bullet$ & $\circ$ & $\bigcirc$ & $\bigcirc$ & $\circ$ & 0.141476 & 0.057309 & 1.000000 \\
\hline 3 & $\bullet$ & $\bullet$ & $\circ$ & $\bullet$ & $\bigcirc$ & $\bullet$ & 0.096612 & 0.096612 & 1.000000 \\
\hline
\end{tabular}

Solution coverage: 0.306422

Solution consistency: 1.000000

Table 5. Causal Configurations Leading to Int

\begin{tabular}{|c|c|c|c|c|c|c|c|c|c|}
\hline \multicolumn{10}{|c|}{ Int $=\mathrm{f}($ Sen, Tecn, Soc, Asyn, Syn, Ext $)$} \\
\hline \multirow[t]{2}{*}{ Configurations } & Sen & Tec & Soc & Asyn & Syn & Ext & \multicolumn{2}{|c|}{ Coverage } & Consistency \\
\hline & & & & & & & raw & unique & \\
\hline 1 & $\circ$ & $\circ$ & • & $\mathrm{O}$ & $\mathrm{O}$ & $\circ$ & 0.187500 & 0.102500 & 0.819672 \\
\hline 2 & $\circ$ & $\bullet$ & $\circ$ & $\mathrm{O}$ & $\mathrm{O}$ & $\circ$ & 0.168750 & 0.083750 & 0.795188 \\
\hline \multicolumn{10}{|c|}{ Solution coverage: 0.271250} \\
\hline Solution consis & $y: 0.8$ & 1893 & & & & & & & \\
\hline
\end{tabular}

Table 6. Causal Configurations Leading to $\sim$ Don

\begin{tabular}{|c|c|c|c|c|c|c|c|c|c|}
\hline \multicolumn{10}{|c|}{$\sim$ Don $=\mathrm{f}($ Sen, Tecn, Soc, Asyn, Syn, Ext) } \\
\hline Configurations & Sen & Tec & Soc & Asyn & Syn & Ext & Coverage & & Consistency \\
\hline & & & & & & & raw & unique & \\
\hline 1 & $\mathrm{O}$ & $\mathrm{O}$ & & $\circ$ & - & $\circ$ & 0.210283 & 0.127783 & 1.000000 \\
\hline 2 & $\mathrm{O}$ & $\mathrm{O}$ & $\cdot$ & & ○ & $\circ$ & 0.165000 & 0.082500 & 1.000000 \\
\hline \multicolumn{10}{|c|}{ Solution coverage: 0.292783} \\
\hline Solution consis & cy: 1. & 00000 & & & & & & & \\
\hline
\end{tabular}

Table 7. Causal Configurations Leading to $\sim$ Int

\begin{tabular}{|c|c|c|c|c|c|c|c|c|c|}
\hline \multicolumn{10}{|c|}{$\sim$ Int $=$ f(Sen, Tecn, Soc, Asyn, Syn, Ext) } \\
\hline \multirow[t]{2}{*}{ Configurations } & \multirow[t]{2}{*}{ Sen } & \multirow[t]{2}{*}{ Tec } & \multirow[t]{2}{*}{ Soc } & \multirow[t]{2}{*}{ Asyn } & \multirow[t]{2}{*}{ Syn } & \multirow[t]{2}{*}{ Ext } & \multicolumn{2}{|c|}{ Coverage } & \multirow[t]{2}{*}{ Consistency } \\
\hline & & & & & & & raw & unique & \\
\hline 1 & $\mathrm{O}$ & $\mathrm{O}$ & & $\circ$ & - & $\mathrm{O}$ & 0.140188 & 0.085188 & 1.000000 \\
\hline 2 & $\mathrm{O}$ & $\mathrm{O}$ & $\bullet$ & & - & $\mathrm{O}$ & 0.110000 & 0.055000 & 1.000000 \\
\hline 3 & - & • & $\mathrm{O}$ & - & $\mathrm{O}$ & $\mathrm{O}$ & 0.251855 & 0.251855 & 0.904869 \\
\hline \multicolumn{10}{|c|}{ Solution coverage: 0.447044} \\
\hline Solution consist & 0.9 & 082 & & & & & & & \\
\hline
\end{tabular}




\section{Discussion}

There is a single necessary condition regarding the absence of knowledge collection, which is not engaging in social activities. Not participating in social activities seems to be an important antecedent to the absence of knowledge collection. There is no solution of configurations leading to the absence of knowledge collection meaning there are no sufficient causal conditions. Thus, not engaging in social activities is a necessary, yet not sufficient condition of to the absence of knowledge collection. Results reflect the described assumptions of fsQCA:

a) There are alternative (more than one) configurations of causal conditions leading to the outcome (and its absence). There are two alternative configurations leading to knowledge collection; three alternative pathways leading to knowledge donation, and two possible combinations of causal conditions leading to knowledge exchange. It seems important to participate in social activities and use synchronous tools in order to collect knowledge in the FSC. According to our findings, two out of the three configurations leading to knowledge donation are also pathways leading to knowledge exchange, suggesting that members that most donate are engage in collecting also (high scores for both knowledge donation and knowledge collection results in high scores for knowledge exchange). Not using synchronous tools is present in all the configurations leading the knowledge donation and knowledge exchange, indicating such tools may not be decisive for those behaviors. Regarding the configurations leading to the absence of the outcomes in the study, there is no solution for the behaviors of the absence of knowledge collection, meaning the communities' members always collect knowledge. There are two pathways leading to the absence of knowledge donation, reflecting patterns of less generous members, and three configurations leading to the absence of knowledge exchange, corresponding to patterns of members there are less intensive in knowledge exchange. Our findings show that, two out of the three configurations leading to the absence of knowledge exchange are similar to the two pathways leading to the absence of knowledge donation, suggesting that patterns reflecting less engagement in knowledge exchange are coincident to the ones regarding less knowledge donation. There are three configurations leading to knowledge donation and only two alternative ones to the absence of knowledge donation, which seems to suggest that knowledge donation in this FSCs is more possible to occur than the absence of knowledge donation. Regarding knowledge exchange, results show that are three configurations leading to the absence of knowledge exchange and only two alternative ones to knowledge exchange, which seems to suggest that it is less common to be intensively engaged in knowledge exchange in this FSCs.

b) There are several causal configurations capable to produce the same outcome (equifinality). There is evidence in support of equifinality, since there are several pathways leading to the same outcome, as well as its absence. Such results are very important for the FSCs leaders/managers dealing with the contributions of the communities' members. Regarding the pathways leading to the absence of the outcomes, not having configurations leading to the absence of knowledge collection clearly shows that members benefit from the FSC, at least there is no way of not collecting knowledge when being a member. On the other hand, our findings bring important information for FSC leaders/managers on the drawbacks of the FSCs regarding the existing patterns of the absence of knowledge donation and the absence of knowledge 
exchange. There are two alternative configurations leading to selfish behaviors of not donating knowledge and three pathways to least intensive knowledge exchange in this communities.

c) The causal conditions of configurations leading to the outcome may differ from the causal conditions leading to its absence (asymmetry). The use of this technique provides autonomous solutions of causal combinations leading to the presence and the absence of the outcomes (knowledge collection, knowledge donation and knowledge exchange intensity). The configurations leading to the absence of the outcomes do not correspond to symmetrical configurations of the ones leading to the presence of the outcome. In this study there is a very visible example of this asymmetry, because there is no solution leading to the absence of knowledge collection and there are two causal configurations leading to knowledge collection.

\section{Conclusions}

Studies regarding the roles and activities in FSCs are normally focused around the technical activities (Bitzer \& Schröder, 2005; Reis \& Fortes, 2002) or the hierarchical structure of the roles (Jensen \& Scacchi, 2007; Madanmohan \& Navelkar, 2004), not exploring the social activities that are also important for the FSC. The social dimension is important for the members of the community (Bonaccorsi \& Rossi, 2003; Iskoujina \& Roberts, 2015; Ulhoi, 2004). Social motivations, like fun and social ties, are antecedents of knowledge sharing in FSCs (Balle \& Oliveira, 2015). Thus, people that don't participate in social activities do not collect knowledge, because the social aspects are directly linked to the hedonistic and philosophical motivations of the participants. The main activity of the community is technical, even the participants that do not engage in social activities have other boundaries that make them continue to collect knowledge on the community. The manuscript delivers an original contribution not previously addressed in literature regarding knowledge sharing patterns in FSCs.

\section{Weaknesses and Next Steps}

The results offer research opportunities to further study conditions supporting and preventing knowledge collection, knowledge donation and knowledge exchange. Limitations apply regarding the conditions used in the study and the restrictions related to the method used. The constraints of this study regarding its qualitative nature regard the lack of generalization of results. This study was applied in only one community, which can result in some biases. Future studies could use data from other kinds of communities of practice, including corporative FSCs. The comparison between the communities of different realities can decrease biases and lead to robust conclusions.

\section{Acknowledgement}

We are grateful for the support provided by CAPES (Coordenação de Aperfeiçoamento de Pessoal de Nível Superior - Brazil, scholarship Programa de Doutorado-sanduíche no Exterior/ Processo $\mathrm{n}^{\mathrm{o}}$ 88881.132892/2016-01), CNPq (Conselho Nacional de Desenvolvimento Científico e Tecnológico - Brazil) and FCT (Fundação para a Ciência e Tecnologia - Portugal) under the project UID/SOC/04521/2013. 


\section{References}

Alavi, M., \& Leidner, D. E. (2001). Knowledge management and knowledge management systems: Conceptual foundations and research issues. MIS Quarterly, 25(1), 107-136.

Barcellini, F., Détienne, F., Burkhardt, J. M., \& Sack, W. (2008). A socio-cognitive analysis of online design discussions in an open source software community. Interacting with Computers, 20(1), 141-165.

Bitzer, J., \& Schröder, P. J. (2005). Bug-fixing and code-writing: The private provision of open source software. Information Economics and Policy, 17(3), 389-406.

Bonaccorsi, A., \& Rossi, C. (2003). Why open source software can succeed. Research Policy, 32(7), 1243-1258.

Brown, J. S., \& Duguid, P. (1998). Organizing knowledge. California Management Review, 40(3), 90-111.

Carillo, K., \& Okoli, C. (2008). The open source movement: A revolution in software development. Journal of Computer Information Systems, 49(2), 1-9.

Chen, C. S., Chang, S. F., \& Liu, C. H. (2012). Understanding knowledge-sharing motivation, incentive mechanisms, and satisfaction in virtual communities. Social Behavior and Personality: An International Journal, 40(4), 639-647.

Chou, S. W. (2005). Knowledge creation: Absorptive capacity, organizational mechanisms, and knowledge storage/retrieval capabilities. Journal of Information Science, 31(6), 453-465.

Crilly, D, Hansen, M., Pedersen, E., \& Perrini. F. (2012). Faking it or muddling through? Understanding decoupling in response to stakeholder pressures. Academy of Management Journal, 55(6), 1429-1449.

Crilly, D. (2011). Predicting stakeholder orientation in the multinational enterprise: A mid-range theory. Journal of International Business Studies, 42, 694-717.

Daghfous, A., \& Ahmad, N. (2015). User development through proactive knowledge transfer. Industrial Management \& Data Systems, 115(1), 158-181.

de Laat, P. B. (2007). Governance of open source software: State of the art. Journal of Management \& Governance, 11(2), 165-177.

Demazière, D., Horn, F., \& Zune, M. (2007). The functioning of a free software community: Entanglement of three regulation modes-control, autonomous and distributed. Science \& Technology Studies, 20(2), 34-54.

du Plessis, M. (2008). The strategic drivers and objectives of communities of practice as vehicles for knowledge management in small and medium enterprises. International Journal of Information Management, 28(1), 61-67.

Endres, M., Endres, S. P., Chowdhury, S. K., \& Alam, I. (2007). Tacit knowledge sharing, selfefficacy theory, and application to the Open Source community. Journal of Knowledge Management, 11(3), 92-103. 
Fiss, P. C. (2007). A set-theoretic approach to organizational configurations. Academy of Management Review, 32(4), 1180-1198.

Fiss, P. C. (2011). Building better causal theories: A fuzzy set approach to typologies in organization research. Academy of Management Journal, 54, 393-420.

Fiss, P. C., Sharapov, D., \& Conqvist, L. (2013). Opposites attract? Opportunities and challenges for integrating large-N QCA and econometric analysis. Political Research Quarterly, $66(1), 191-235$.

Gonzalez, J. A., \& Chakraborty, S. (2014). Expatriate knowledge utilization and MNE performance: A multilevel framework. Human Resource Management Review, 24(4), 299-312.

Grant, R. M. (1996). Toward a knowledge-based theory of the firm. Strategic Management Journal, 17(S2), 109-122.

Hendriks, P. (1999). Why share knowledge? The influence of ICT on the motivation for knowledge sharing. Knowledge and Process Management, 6(2), 91-100.

Hsu, M. H., Ju, T. L., Yen, C. H., \& Chang, C. M. (2007). Knowledge sharing behavior in virtual communities: The relationship between trust, self-efficacy, and outcome expectations. International Journal of Human-Computer Studies, 65(2), 153-169.

Iskoujina, Z., \& Roberts, J. (2015). Knowledge sharing in open source software communities: motivations and management. Journal of Knowledge Management, 19(4), 791-813.

Jensen, C., \& Scacchi, W. (2007, May). Role migration and advancement processes in OSSD projects: A comparative case study. In 29th International Conference on Software Engineering, 2007. (pp. 364-374). IEEE.

Karkoulian, S., Harake, N. A., \& Messarra, L. C. (2010). Correlates of organizational commitment and knowledge sharing via emotional intelligence: An empirical investigation. The Business Review, 15(1), 89-96.

Krishnamurthy, S. (2003). A managerial overview of open source software. Business Horizons, $46(5), 47-56$.

Lave, J., \& Wenger, E. (1991). Situated learning: Legitimate peripheral participation. Cambridge, UK: Cambridge University Press.

Madanmohan, T. R., \& Navelkar, S. (2004). Roles and knowledge management in online technology communities: An ethnography study. International Journal of Web Based Communities, 1(1), 71-89.

Majchrzak, A., Rice, R. E., King, N., Malhotra, A., \& Ba, S. (2000). Computer-mediated interorganizational knowledge-sharing: Insights from a virtual team innovating using a collaborative tool. Information Resources Management Journal, 13(1), 44-53.

Matherly, L. L., \& Al Nahyan, S. S. (2015). Workplace quotas: Building competitiveness through effective governance of national-expatriate knowledge transfer and development 
of sustainable human capital. International Journal of Organizational Analysis, 23(3), 456-471.

Mohanty, R. P. (2003). Towards knowledge management: a case study. International Journal of Information Technology and Management, 2(3), 197-213.

Molloy, J. C. (2011). The open knowledge foundation: Open data means better science. PLoS biology, 9(12), e1001195.

Nobre, F. S., \& Walker, D. S. (2011). An ability-based view of the organization: Strategicresource and contingency domains. The Learning Organization, 18(4), 333-345.

O'Reilly, T. (1999). Lessons from open-source software development. Communications of the $A C M, 42(4), 32-37$.

Panahi, S., Watson, J., \& Partridge, H. (2013). Towards tacit knowledge sharing over social web tools. Journal of Knowledge Management, 17(3), 379-397.

Ragin, C. C. (2005). From fuzzy sets to crisp truth tables. Tucson, Arizona: Department of Sociology, University of Arizona.

Ragin, C. C. (2006). User's guide to fuzzy-set/qualitative comparative analysis 2.0. Tucson, Arizona: Department of Sociology, University of Arizona.

Ragin, C. C. (2008). Redesigning social inquiry: Fuzzy sets and beyond. Chicago, IL: University of Chicago Press.

Ranjan, J. (2011). Study of sharing knowledge resources in business schools. The Learning Organization, 18(2), 102-114.

Reis, C. R., \& Fortes, R. P. (2002, February). An overview of the software engineering process and tools in the Mozilla project. In C. Gacek \& B. Arief. (Eds.) Proceedings of the Open Source Software Development Workshop (pp. 155-175). Newcastle upon Tyne, UK.

Rihoux, B., \& Ragin, C. C. (2009). Configurational comparative methods: Qualitative comparative analysis (QCA) and related Research. Los Angeles, CA: Sage Publication.

Scarso, E., \& Bolisani, E. (2008). Communities of practice as structures for managing knowledge in networked corporations. Journal of Manufacturing Technology Management, 19(3), 374-390.

Shen, X. (2005). Developing country perspectives software: Intellectual property and open source. International Journal of IT Standards and Standardization Research, 3(1), 21-43.

Shin, M. (2004). A framework for evaluating economics of knowledge management systems. Information \& Management, 42(1), 179-196.

Sommerville, I. (2003). Engenharia de software (Vol. 6, pp. 05-12). São Paulo, Brazil: Addison Wesley.

Song, J. (2014). Subsidiary absorptive capacity and knowledge transfer within multinational corporations. Journal of International Business Studies, 45(1), 73-84. 
Stallman, R. M. (2015). What is free software? In Stallman, R. (Ed.) Free Society, Free Society, (pp. 3-8) Retrieved from https://www.gnu.org/doc/fsfs3-hardcover.pdf

Tseng, S. M. (2010). The correlation between organizational culture and knowledge conversion on corporate performance. Journal of Knowledge Management, 14(2), 269-284.

Ulhøi, J. P. (2004). Open source development: A hybrid in innovation and management theory. Management Decision, 42(9), 1095-1114.

Van Den Hooff, B., \& De Ridder, J. A. (2004). Knowledge sharing in context: The influence of organizational commitment, communication climate and $\mathrm{CMC}$ use on knowledge sharing. Journal of Knowledge Management, 8(6), 117-130.

Velmurugan, M., Kogilah, N., \& Devinaga, R. (2010). Knowledge sharing in virtual teams in malaysia: Its benefits and barriers. Journal of Information \& Knowledge Management, 9(2), 145-159.

Wasko, M. M., \& Faraj, S. (2005). Why should I share? Examining social capital and knowledge contribution in electronic networks of practice. MIS Quarterly, 29(1), 35-57.

Wenger, E., McDermott, R. A., \& Snyder, W. (2002). Cultivating communities of practice: A guide to managing knowledge. Cambridge, MA: Harvard Business Press.

Wenger, E. C., \& Snyder, W. M. (2000). Communities of practice: The organizational frontier. Harvard Business Review, 78(1), 139-146.

Wenger, E., White, N., Smith, J. D., \& Rowe, K. (2005). Technology for communities. In Langelier, L. (Ed.), Guide de mise en place et d'animation de communautés de pratique intentionnelles: travailler, apprendre et collaborer en réseau. Montréal: CEFRIO.

Yang, C., \& Chen, L. C. (2007). Can organizational knowledge capabilities affect knowledge sharing behavior? Journal of Information Science, 33(1), 95-109.

Ye, Y., \& Kishida, K. (2003, May). Toward an understanding of the motivation open source software developers. In Proceedings of the 25th international conference on software engineering (pp. 419-429). IEEE Computer Society.

\section{Authors' Biographies}

Andrea Raymundo Balle obtained her M.Sc. in Business Administration from Pontifical Catholic University of Rio Grande do Sul (PUCRS). She is currently a doctoral candidate at PUCRS, School of Business, Brazil. Her research interests include Knowledge Management, Knowledge Sharing and Management Information Systems.

Carla Curado is an Associate Professor at the Department of Management, ISEG - Lisbon School of Economics and Management, University of Lisbon, Portugal. She received her Ph.D. in management from the Technical University of Lisbon. Her current research interests include Knowledge Management, Human Resources Management, Organizational Behavior, and Intellectual Capital. She has published numerous articles on these topics in outlets such as the Journal of Business Research, Computers in Human Behavior, Journal of Knowledge 
Management, Management Decision or Creativity and Innovation Management.

Mírian Oliveira obtained her doctoral degree in Business Administration from the Federal University of Rio Grande do Sul (UFRGS) in 1999. She is a professor and researcher at Pontifical Catholic University of Rio Grande do Sul (PUCRS), School of Business, Brazil. Her current research interests include Knowledge Management, Knowledge Sharing and Research Method. 